\title{
The Most Economical Power Factor Correction According to Tariff Structures in Egypt
}

\author{
Ahmed Faheem Zobaa, Senior Member, IEEE, and Mohamed Mamdouh Abdel Aziz, Member, IEEE
}

\begin{abstract}
A method of applying power-factor (PF) correction capacitors is discussed based on net savings maximization according to Egyptian's Tariff. Test results from examples taken from existing publications are presented. The purpose of this application technique is to utilize existing electrical distribution equipment in the installation of very large values of $P F$ correction capacitors. It is concluded that $L C$ compensators can be installed, thus providing maximum benefits from penalty elimination, system losses reduction, release of system transformer capacity, and minimum switching transients. Paybacks of less than one year can be expected.
\end{abstract}

Index Terms-Harmonics, power factor, reactive power optimization.

\section{NOMENCLATURE}

$\mathrm{R}_{\mathrm{LK}}, \mathrm{X}_{\mathrm{LK}}$

Load resistance and reactance at harmonic number K (in ohms).

$\mathrm{G}_{\mathrm{LK}}, \mathrm{B}_{\mathrm{LK}}$ Load conductance and susceptance at harmonic number K (in ohms).

$\mathrm{R}_{\mathrm{TK}}, \mathrm{X}_{\mathrm{TK}}$

$\mathrm{X}_{\mathrm{L}}, \mathrm{X}_{\mathrm{C}}$ Thevenin resistance and reactance at harmonic number K (in ohms).

$\mathrm{R} \quad$ Resistance of the compensator reactor (in Fundamental inductive and capacitive reactance of the compensator (in ohms). ohms).

IS Root mean square (rms) value of supply cur-

$\mathrm{I}_{\mathrm{SK}}$ rent (in amperes).

$\mathrm{I}_{\text {LK }}$

$\mathrm{I}_{\mathrm{CK}}$

$\mathrm{V}_{\mathrm{L}}$

$\mathrm{V}_{\mathrm{SK}}$

$\mathrm{V}_{\mathrm{LK}}$

$\mathrm{PF}$

$\mathrm{dPF}$

$\eta$

TL
Supply current at harmonic number K (in amperes).

Load harmonic current (in amperes).

Capacitor current at harmonic number K (in amperes).

RMS value of load voltage (in volts).

Supply voltage at harmonic number K (in volts).

Load voltage at harmonic number $\mathrm{K}$ (in volts).

Load power factor (in per unit).

Load displacement power factor (in per unit).

Network transmission efficiency (in percent).

Loss in Thevenin resistance (in kilowatts).

Manuscript received April 8, 2003; revised August 13, 2003. Paper no. TPWRD-00163-2003.

The authors are with Electrical Power and Machines Department, Faculty of Engineering, Cairo University, Giza 12613, Egypt (e-mail: a.zobaa@eng.cu.edu.eg).

Digital Object Identifier 10.1109/TPWRD.2004.839178

\section{INTRODUCTION}

$\mathbf{E}$ LECTRICITY tariff structures in Egypt are fairly complex, especially for large industrial users. Electricity tariffs are designed to recover the cost to the utility of both providing the equipment to generate the electricity and the cost of operating the equipment. The first category of charges is sometimes called "fixed charges," because these charges help the utility to recover the costs associated with providing the installed generating equipment, transmission, and distribution. The levy imposed by the utility to recover these costs is generally built into the charges for peak demand and power factor (PF).

Demand charges are generally based on either an actual measured peak demand or a contracted peak demand. Generally, peak demand is the highest kilovolt-ampere continued for a 15-min "window" measured over four windows during any one calendar month. The utility must provide the generating, transmission, and distribution equipment capacity to meet a user's peak electric demand, even if that maximum electric demand occurs for only a short period of time. Hence, the customer can incur substantial costs for a short duration of high electricity demand. In addition, because the demand charges are based on the higher contract peak demand or actual measured peak demand, the customer who contracts for a significantly higher peak demand than actually required will also incur significantly higher electricity costs.

The second category of charges is sometimes called "variable charges" because these charges help the utility recover their costs of operating the equipment (e.g., labor, fuel, taxes, and other costs of operation). The cost of operation depends on the amount of electricity generated. These costs are recovered in the kilowatt-hour charges.

In Egypt, utilities impose a penalty in the form of higher charges for customers with contracted loads greater than $500 \mathrm{~kW}$ whose PF is less 0.9. From the customer's point of view, this penalty should be sufficient to motivate the installation of PF correction equipment. Aside from decreasing the electric bill (or actually resulting in a bonus), other advantages of PF correction include increasing internal electrical distribution system capacity, reducing distributing system losses, and enhancing voltage stability. The following are the possible benefits that can be achieved by correcting the consumer's PF value [1].

\section{A. Elimination of the Lagging PF Penalty}

The PF penalty is a multiplier applied to the normal kilowatthour consumption charges. The penalty is based on an annual 
average PF, calculated from kilowatt-hours ( $\mathrm{kWh}$ ) and kvarh meter readings as follows:

$$
\text { Average annual } \mathrm{PF}=\frac{\mathrm{kWh}}{\sqrt{\mathrm{kWh}^{2}+\mathrm{k} v a r \mathrm{~h}^{2}}} .
$$

When the average annual PF is less than $90 \%$ but greater or equal to $70 \%$, the penalty is calculated as follows:

$$
\text { Penalty }=(0.9-\mathrm{PF}) * \mathrm{kWh} \text { charges. }
$$

When the average annual PF is less than $70 \%$, the penalty is

$$
\text { Penalty }=\left[(0.9-0.7)+\frac{3}{2}(0.7-\mathrm{PF})\right] * \mathrm{kWh} \text { charges. }
$$

If the consumer does not correct the PF, the penalty increases after three months to

$$
\text { Penalty }=2 *(0.9-\mathrm{PF}) * \mathrm{kWh} \text { charges. }
$$

The utility also has the right to discontinue service if the consumer does not correct the PF within another six months.

\section{B. Reduction in Contract Demand}

The contract demand is the demand that the supplier of electric service agrees to have available for delivery. According to the Egyptian tariff structure, increasing the PF may allow the consumer to reduce his or her contracted power. This results in the use of a different scale for calculating the cost of kilowatt-hour consumption. The effect is to use smaller block sizes at higher unit energy costs and larger block sizes for the cheaperrate blocks.

\section{Bonus due to Overcorrected PF}

According to the Egyptian tariff structure, a bonus is offered to customers when they maintain an average annual PF higher than $92 \%$ and up to a maximum of $95 \%$. This can be calculated by the following:

$$
\text { Bonus }=\frac{\mathrm{PF}-0.92}{2} * \mathrm{kWh} \text { charges. }
$$

\section{Reduction of Internal Distribution System Losses}

With active power held constant, as PF decreases, the required apparent power increases. As a result, the electrical system resistance losses are increased. Although these losses are small ( $2.5 \%$ to $7.5 \%$ of a typical industrial load's yearly energy consumption) [2], the effect is much more pronounced on a national scale.

\section{E. Increased Distribution System Capacity}

Low PF cuts down distribution system capacity. Similar capacity degradation is possible with cables, circuit breakers, and other electrical equipment. The capacity of all of this equipment to provide useful power is reduced by low PF. In effect, increasing PF will result in increased capacity in existing electrical distribution systems. This can help offset or reduce expenses for additional system capacity.

\section{F. Enhanced Voltage Profile}

While not a reason in itself for installing PF improvement equipment, better voltage stability is usually an additional benefit of PF correction.

This paper presents a method for maximizing the net savings due to PF correction at the load bus where it is desired to maintain the PF and total harmonic distortion of the voltage $V T H D$ at a desired level by using the Penalty Function method as a tool of optimization. It is assumed that both the equivalent source and load are considered to generate harmonics. Also, It is assumed that the load harmonics are not sufficiently serious to suggest tuned filters, but when combined with source harmonics, the use of a pure capacitive compensator would degrade $\mathrm{PF}$ and overload equipment. Consequently, an LC compensator is selected [3].

\section{Industrial Motive POWER TARIFF}

The large industrial motive power tariff applies to three major classes of customers: public sector industries, national private sector industries, and investment sector companies.

The tariff is based on three elements: a demand charge, a consumption charge, and a PF charge. In addition, for private and investment sector companies, a fuel adjustment charge may be added. Each of these charges is discussed below.

\section{A. Annual Demand Charge}

The electric demand charge is based on the highest of one of three demands: the contracted power in kilowatts, the contracted power in kilovolt-amperes times 0.9 , and the actual recorded power in kilowatts. The annual cost per kilowatt of demand is currently 87.6 LE (Egyptian pounds). Hence, the highest of the three demand times 87.6 LE yields the annual demand charge.

\section{B. Annual Consumption Charge}

The consumption charge is based on annual kilowatt-hours of electricity used. The annual cost per kilowatt-hours of demand is currently 0.1535 LE (Egyptian pounds). Hence, the annual consumption times 0.1535 LE yields the annual consumption charge.

\section{Annual PF Penalty}

The final element of the industrial tariff is the cost of the PF penalty.

\section{CASE Study AND ITS Simulation}

Fig. 1 is an example illustrating the case study of an industrial plant [4]. The 60-cycle supply bus voltage is $4.16 \mathrm{kV}$. For conciseness, the actual plant loading is consolidated in this listing.

Induction motors

$1200 \mathrm{~kW}$ at $0.80 \mathrm{PF}=900 \mathrm{kvars}$

$900 \mathrm{~kW}$ at $0.70 \mathrm{PF}=918 \mathrm{kvars}$. 


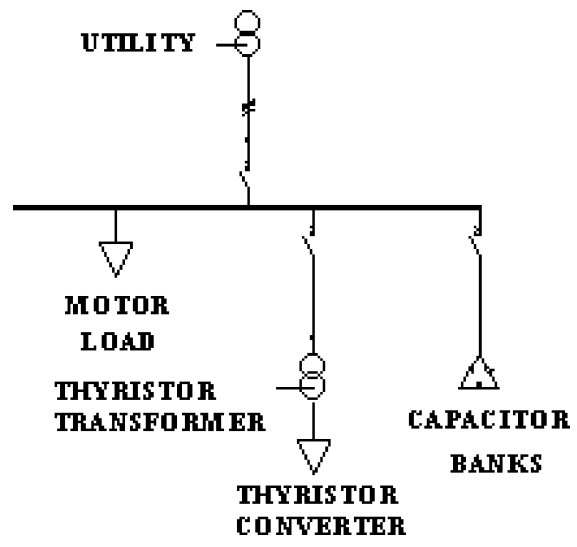

Fig. 1. Case under study.

Thyristor dc drives

$$
\begin{aligned}
600 \mathrm{~kW} \text { at } 0.70 \mathrm{PF} & =612 \mathrm{kvars} \\
1100 \mathrm{~kW} \text { at } 0.50 \mathrm{PF} & =1905 \text { kvars. }
\end{aligned}
$$

Other

$$
\begin{aligned}
& 1300 \mathrm{~kW} \text { at } 0.90 \mathrm{PF}=630 \mathrm{kvars} \\
& 5100 \mathrm{~kW} \quad 4965 \text { kvars. }
\end{aligned}
$$

The above list illustrates the low displacement power factor dPF (71.65\%) associated with this load.

Fig. 2 is a single-phase equivalent circuit of a nonsinusoidal bus of Fig. 1 with an LC compensator.

The Thevenin voltage source representing the utility supply and the harmonic current source representing the nonlinear load is

$$
\mathrm{v}_{\mathrm{S}}(\mathrm{t})=\sum_{\mathrm{K}} \mathrm{v}_{\mathrm{SK}}(\mathrm{t})
$$

and

$$
\mathrm{i}_{\mathrm{LK}}(\mathrm{t})=\sum_{\mathrm{K}} \mathrm{i}_{\mathrm{LK}}(\mathrm{t})
$$

where $K$ is the order of harmonic present.

The $K$ th harmonic Thevenin source and load impedances are

$$
\mathrm{Z}_{\mathrm{TK}}=\mathrm{R}_{\mathrm{TK}}+\mathrm{j} \mathrm{X}_{\mathrm{TK}}
$$

and

$$
\mathrm{Z}_{\mathrm{LK}}=\mathrm{R}_{\mathrm{LK}}+\mathrm{j} \mathrm{X}_{\mathrm{LK}}
$$

or

$$
\mathrm{Y}_{\mathrm{LK}}=\mathrm{G}_{\mathrm{LK}}-\mathrm{j} \mathrm{B}_{\mathrm{LK}} \text {. }
$$

To simplify the analysis, only the load model using the respective active and reactive powers at the fundamental frequency is considered while sizing the compensators. The utility is often represented by an impedance, which is found from

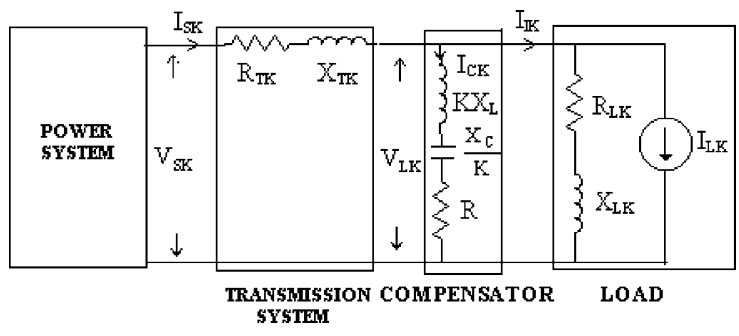

Fig. 2. Single-phase equivalent circuit for $K$ th harmonic with shunt LC compensator.

the short circuit test [5]. This model, Fig. 2, is adequate where $V T H D$ is less than $10 \%$ [6].

Let $Z_{\mathrm{CLK}}=Z_{\mathrm{CK}}$ be in parallel with $Z_{\mathrm{LK}}$

Then

$$
\mathrm{Z}_{\mathrm{CLK}}=\frac{\left(\mathrm{R}_{\mathrm{CLK}}+\mathrm{j} \mathrm{X}_{\mathrm{CLK}}\right)}{\left(\mathrm{Z}_{\mathrm{LK}}+\mathrm{Z}_{\mathrm{CK}}\right)}
$$

where

$$
\begin{aligned}
& R_{C L K}=R_{L K}-X_{L K}\left(K X_{L}-\frac{X_{C}}{K}\right) \\
& X_{C L K}=R_{L K}+R_{L K}\left(K X_{L}-\frac{X_{C}}{K}\right) .
\end{aligned}
$$

Let $Z_{\mathrm{TLK}}=Z_{\mathrm{TK}}$ be in parallel with $Z_{\mathrm{LK}}$.

Then

$$
\mathrm{Z}_{\mathrm{TLK}}=\frac{\left(\mathrm{R}_{\mathrm{TLK}}+\mathrm{j} \mathrm{X}_{\mathrm{TLK}}\right)}{\left(\mathrm{Z}_{\mathrm{TK}}+\mathrm{Z}_{\mathrm{LK}}\right)}
$$

where

$$
\begin{aligned}
& \mathrm{R}_{\mathrm{TLK}}=\mathrm{R}_{\mathrm{TK}} \mathrm{R}_{\mathrm{LK}}-\mathrm{X}_{\mathrm{TK}} \mathrm{X}_{\mathrm{LK}} \\
& \mathrm{X}_{\mathrm{TLK}}=\mathrm{R}_{\mathrm{TK}} \mathrm{X}_{\mathrm{LK}}+\mathrm{R}_{\mathrm{LK}} \mathrm{X}_{\mathrm{TK}} .
\end{aligned}
$$

From Fig. 2

$$
\begin{aligned}
\mathrm{V}_{\mathrm{SK}} & =\mathrm{I}_{\mathrm{SK}} *\left(\mathrm{R}_{\mathrm{TK}}+\mathrm{j} \mathrm{X}_{\mathrm{TK}}\right)+\mathrm{V}_{\mathrm{LK}} \\
& =\mathrm{I}_{\mathrm{SK}} *\left(\mathrm{R}_{\mathrm{TK}}+\mathrm{j} \mathrm{X}_{\mathrm{TK}}\right)+\left(\mathrm{I}_{\mathrm{SK}}-\mathrm{I}_{\mathrm{LK}}\right) * \mathrm{Z}_{\mathrm{CLK}} .
\end{aligned}
$$

By simplification of the above equation and using (8)-(12), the supply current is obtained

$$
I_{S K}=\frac{V_{S K}(A R+j B R)+I_{L K}(C R)}{A_{I K}+j A_{J K}} .
$$

Then, the load voltage is given by

$$
\mathrm{V}_{\mathrm{LK}}=\frac{\mathrm{V}_{\mathrm{SK}}(\mathrm{CR})-\mathrm{I}_{\mathrm{LK}}(\mathrm{DR} * \mathrm{ER})}{\mathrm{A}_{\mathrm{IK}}+\mathrm{j} \mathrm{A}_{\mathrm{JK}}}
$$

and the compensator current is given by

$$
I_{C K}=\frac{V_{S K}\left(Z_{L K}\right)-I_{L K}(E R)}{A_{I K}+j A_{J K}}
$$

where

$$
\begin{aligned}
& \mathrm{AR}=\mathrm{R}+\mathrm{R}_{\mathrm{LK}} \\
& \mathrm{BR}=\left(\mathrm{X}_{\mathrm{LK}}+\mathrm{KX}_{\mathrm{L}}-\frac{\mathrm{X}_{\mathrm{C}}}{\mathrm{K}}\right) \\
& \mathrm{CR}=\mathrm{R}_{\mathrm{CLK}}+\mathrm{j} \mathrm{X}_{\mathrm{CLK}}
\end{aligned}
$$




$$
\begin{aligned}
\mathrm{DR} & =\mathrm{R}+\mathrm{j}\left(\mathrm{KX}_{\mathrm{L}}-\frac{\mathrm{X}_{\mathrm{C}}}{\mathrm{K}}\right) \\
\mathrm{ER} & =\mathrm{R}_{\mathrm{TLK}}+\mathrm{j} \mathrm{X}_{\mathrm{TLK}} \\
\mathrm{A}_{\mathrm{IK}} & =\mathrm{R}_{\mathrm{TLK}}+\mathrm{R}\left(\mathrm{R}_{\mathrm{LK}}+\mathrm{R}_{\mathrm{TK}}\right)-\left(\mathrm{X}_{\mathrm{LK}}+\mathrm{X}_{\mathrm{TK}}\right)\left(\mathrm{KX}_{\mathrm{L}}-\frac{\mathrm{X}_{\mathrm{C}}}{\mathrm{K}}\right) \\
\mathrm{A}_{\mathrm{JK}} & =\mathrm{X}_{\mathrm{TLK}}+\mathrm{R}\left(\mathrm{R}_{\mathrm{LK}}+\mathrm{X}_{\mathrm{TK}}\right)+\left(\mathrm{R}_{\mathrm{LK}}+\mathrm{R}_{\mathrm{TK}}\right)\left(\mathrm{KX}_{\mathrm{L}}-\frac{\mathrm{X}_{\mathrm{C}}}{\mathrm{K}}\right) .
\end{aligned}
$$

For capacitors and reactors, volt-ampere ratings are defined as [4]

$$
\mathrm{S}_{\mathrm{C}}=\left[\sum_{\mathrm{K}} \mathrm{I}_{\mathrm{CK}} \frac{\mathrm{X}_{\mathrm{C}}}{\mathrm{K}}\right]\left[\sum_{\mathrm{K}} \mathrm{I}_{\mathrm{CK}}^{2}\right]^{1 / 2} \mathrm{kVA}
$$

and

$$
\mathrm{S}_{\mathrm{L}}=\left[\sum_{\mathrm{K}} \mathrm{I}_{\mathrm{CK}} \mathrm{KX}_{\mathrm{L}}\right]\left[\sum_{\mathrm{K}} \mathrm{I}_{\mathrm{CK}}^{2}\right]^{1 / 2} \mathrm{kVA} .
$$

In (16) and (17), the harmonic voltages are added linearly in the first summation to emphasize the effect of peak (as opposed to rms) voltage on insulation cost.

The variable part of the compensator cost is then

$$
\mathrm{TCOST}=\mathrm{K}_{\mathrm{C}} * \mathrm{~S}_{\mathrm{C}}+\mathrm{K}_{\mathrm{L}} * \mathrm{~S}_{\mathrm{L}}
$$

where $K_{\mathrm{C}}$ and $K_{\mathrm{L}}$ are, respectively, the costs of capacitor and inductor per kilovolt-ampere and considered to be constant parameters and taking as 60.0 L.E./kVA in this study.

\section{OBJeCTIVE FunCtion}

The contracted power was $P_{\mathrm{O}}(5100 \mathrm{~kW})$ at $P F_{\mathrm{O}}(90 \%)$. Therefore, the demand charges were $\left(87.6 \times \mathrm{P}_{\mathrm{O}}\right)$ LE according to the Egyptian tariff. The power is $P_{\mathrm{n}} \mathrm{kW}$ at $P F_{\mathrm{n}}$ after PF correction. Therefore, the demand charges are $\left(87.6 \times \mathrm{P}_{\mathrm{n}}\right)$ LE. By reducing contracted demand from $P_{\mathrm{O}}$ to $P_{\mathrm{n}}$, demand charges were reduced by $\left[87.6 \times\left(\mathrm{P}_{\mathrm{O}}-\mathrm{P}_{\mathrm{n}}\right)\right] \mathrm{LE}$.

Energy savings due to the improvement in plant power factor are [old $\mathrm{kWh}$ charges - new $\mathrm{kWh}$ charges] LE.

Obviously, the PF penalty was eliminated entirely, resulting in savings of $\left[\left(0.9-\mathrm{PF}_{\mathrm{O}}\right) *\right.$ old $\mathrm{kWh}$ charges $] \mathrm{LE}$.

According to a contract between the distribution company and the consumer, a bonus $[((\mathrm{PF}-0.92) / 2) *$ new $\mathrm{kWh}$ charges] is provided to the customer if his or her plant's PF is greater than $92 \%$.

Then, the total annual savings resulting from the PF correction $S_{\mathrm{I}, \text {, is }}$

$$
\begin{aligned}
\mathrm{S}_{\mathrm{I}}= & 87.6 *\left(\mathrm{P}_{\mathrm{O}}-\mathrm{P}_{\mathrm{n}}\right) \\
& +(\text { old } \mathrm{kWh} \text { charges }- \text { new kWh charges }) \\
& +\left(0.9-\mathrm{PF}_{\mathrm{O}}\right) * \text { old } \mathrm{kWh} \text { charges } \\
& +\frac{\mathrm{PF}-0.92}{2} * \text { new } \mathrm{kWh} \text { charges L.E.. }
\end{aligned}
$$

\section{CONSTRAINTS INVOLVED}

\section{A. PF at the Compensated Load Terminals}

$$
\mathrm{PF}=\frac{\mathrm{P}_{\mathrm{L}}}{\mathrm{V}_{\mathrm{L}} \mathrm{I}_{\mathrm{S}}}=\frac{\sum \mathrm{G}_{\mathrm{LK}} \mathrm{V}_{\mathrm{LK}}^{2}}{\sqrt{\sum \mathrm{I}_{\mathrm{SK}}^{2} \sum \mathrm{V}_{\mathrm{LK}}^{2}}}
$$

\section{B. VTHD at the Compensated Load Terminals}

$$
\mathrm{VTHD}=\frac{\sqrt{\sum_{\mathrm{K}>1} \mathrm{~V}_{\mathrm{LK}}^{2}}}{\mathrm{~V}_{\mathrm{L} 1}} .
$$

\section{Effect of Supply Frequency on the AC Resistance}

In most power systems, one can generally assume that the resistance does not change significantly when studying the effects of harmonics of less than the ninth [6]. In this study, it is assumed that

$$
\mathrm{R}_{\mathrm{TK}}=\mathrm{R}_{\mathrm{T}}, \quad \mathrm{R}_{\mathrm{LK}}=\mathrm{R}_{\mathrm{L}}
$$

where $R_{\mathrm{T}}$ is the resistance of the transmission system at the fundamental frequency, and $R_{\mathrm{L}}$ is the resistance of the load at the fundamental frequency.

The reader should refer to [7] and [8] for detailed analysis of distribution systems, loads, and other system elements.

\section{Resonance Constraint}

The expected impedance seen from the Thevenin source is given by

$$
\mathrm{Z}=\mathrm{Z}_{\mathrm{TK}}+\mathrm{Z}_{\mathrm{CLK}} \text {. }
$$

The resonance peaks can be obtained by setting the imaginary part of (23) to zero, resulting in a quadratic equation in $X_{\mathrm{C}}$ and $X_{\mathrm{L}}$ for any given harmonic order $K$

$$
\mathrm{K}_{1}\left(\mathrm{KX}_{\mathrm{L}}-\frac{\mathrm{X}_{\mathrm{C}}}{\mathrm{K}}\right)^{2}+\mathrm{K}_{2}\left(\mathrm{KX}_{\mathrm{L}}-\frac{\mathrm{X}_{\mathrm{C}}}{\mathrm{K}}\right)+\mathrm{K}_{3}=0
$$

where

$$
\begin{aligned}
& \mathrm{K}_{1}=\mathrm{X}_{\mathrm{TK}}+\mathrm{X}_{\mathrm{LK}} \\
& \mathrm{K}_{2}=\mathrm{R}_{\mathrm{LK}}^{2}+\mathrm{X}_{\mathrm{LK}}^{2}+2 \mathrm{X}_{\mathrm{LK}} \mathrm{X}_{\mathrm{TK}} \\
& \mathrm{K}_{3}=\mathrm{R}^{2} \mathrm{X}_{\mathrm{LK}}+\mathrm{X}_{\mathrm{TK}}\left[\left(\mathrm{R}+\mathrm{R}_{\mathrm{LK}}\right)^{2}+\mathrm{X}_{\mathrm{LK}}^{2}\right]
\end{aligned}
$$

The precalculated compensator values for series resonance by taking the solution of (24) where the square root of the discriminant is positive, are used to subdivide the entire search region into smaller regions. In each region, the total maximums are identified leading to the eventual identification of the global maximum of any of the functions. 


\section{E. Standard Ratings of the Capacitors}

IEEE Standard 18-2002 [9] shows that the voltage rating of $4160 \mathrm{~V}$ (terminal-to-terminal) has standard reactive power ratings $\mathrm{Q}_{\mathrm{C}}$ of 50, 100, 150, and 200 kvar for the capacitors. Each value of the reactive power ratings of the particular voltage is used to calculate the corresponding value of $X_{\mathrm{Ci}}$. This value is then substituted into the objective function and constraints to become one variable equation in $X_{\mathrm{L}}$,

Then, the problem becomes

\section{Maximize $\mathrm{S}_{\mathrm{I}}\left(\mathrm{X}_{\mathrm{Ci}}, \mathrm{X}_{\mathrm{L}}\right)$}

Subject to : $\operatorname{PF}\left(\mathrm{X}_{\mathrm{Ci}}, \mathrm{X}_{\mathrm{L}}\right) \geq 90 \%, \operatorname{VTHD}\left(\mathrm{X}_{\mathrm{Ci}}, \mathrm{X}_{\mathrm{L}}\right) \leq 5 \%$,

$$
\mathrm{X}_{\mathrm{Ci}} \text { and } \mathrm{X}_{\mathrm{L}} \text { are not a part of }(24) \text {. }
$$

The value $X_{\mathrm{Ci}}$ is substituted into (25) to become one variable equation in $X_{L}$. Hence, an iterative method is needed to generate the solution. From the experience, the Penalty Function method is chosen since it requires fewer steps and function evaluations [10]-[12].

\section{OptIMIZATION ALGORITHM}

Let the basic optimization problem with inequality constraints be of the form (25). Choose the first value of the standard manufactured reactive power rating of capacitors in kvar [9]

$$
\mathrm{Q}_{\mathrm{Ci}}=\left\{\mathrm{Q}_{\mathrm{C} 1}, \mathrm{Q}_{\mathrm{C} 2} \ldots \mathrm{Q}_{\mathrm{Cn}}\right\}
$$

where $n$ is the number of discrete values available for the particular voltage rating used and $i$ has a starting value of 1 . Using only the selected value of $\mathrm{Qci}$, calculate $\mathrm{X}_{\mathrm{ci}}$ from the following:

$$
\mathrm{X}_{\mathrm{Ci}}=\frac{\mathrm{V}_{\mathrm{S} 1}{ }^{2}}{\mathrm{Q}_{\mathrm{Ci}}} \text {. }
$$

Substitute the value of $X_{\mathrm{Ci}}$ into (25) to become one variable problem in $X_{\mathrm{L}}$, and solve it to get the precalculated inductor values for series resonance. These values are used to subdivide the entire search region into small regions. By using the Penalty Function method, this problem is converted into an unconstrained problem by constructing a function of the form

$$
f\left(X_{L}\right)=S_{1}\left(X_{C i}, X_{L}\right)+\sum_{m} \mu_{m}\left(\max \left[0, g_{m}\left(X_{C i}, X_{L}\right)\right]\right)
$$

where $g_{\mathrm{m}}$ is some function of the constraint, $\mu_{\mathrm{m}}$ is a positive constant known as the penalty parameter, and $\max \left[0, g_{m}\left(X_{C}, X_{L}\right)\right]$ is the commonly used form [12] of the penalty parameter, which is the second part of (26)

$$
\begin{aligned}
& \mathrm{g}_{1}=0.9-\operatorname{PF}\left(\mathrm{X}_{\mathrm{Ci}}, \mathrm{X}_{\mathrm{L}}\right) \\
& \mathrm{g}_{2}=\operatorname{VTHD}\left(\mathrm{X}_{\mathrm{Ci}}, \mathrm{X}_{\mathrm{L}}\right)-0.05 .
\end{aligned}
$$

The suggested search algorithm is discussed below

Step 1) Start with an initial feasible point $X_{\mathrm{C}}^{0}, X_{\mathrm{L}}^{0},(24)$, satisfying all of the constraints with a strict inequality sign. Start with an initial value of $\mu_{\mathrm{m}}>0$, and set $\mathrm{J}=1$ to solve the problem.
TABLE I

SYSTEM PARAMETERS AND SOURCE HARMONICS

\begin{tabular}{c|c|c|c|c}
\hline \hline $\begin{array}{c}\text { PARAMETERS \& } \\
\text { HARMONICS }\end{array}$ & CASE 1 & CASE 2 & CASE 3 & CASE 4 \\
\hline Short Circuit MVA & 150 & 150 & 80 & 80 \\
\hline $\mathrm{R}_{\mathrm{T} 1}(\Omega)$ & 0.01154 & 0.01154 & 0.02163 & 0.02163 \\
\hline $\mathrm{X}_{\mathrm{T} 1}(\Omega)$ & 0.1154 & 0.1154 & 0.2163 & 0.2163 \\
\hline $\mathrm{R}_{\mathrm{L} 1}(\Omega)$ & 1.742 & 1.742 & 1.742 & 1.742 \\
\hline $\mathrm{X}_{\mathrm{L} 1}(\Omega)$ & 1.696 & 1.696 & 1.696 & 1.696 \\
\hline $\mathrm{V}_{\mathrm{S} 1}(\mathrm{~V})$ & 2400 & 2400 & 2400 & 2400 \\
\hline $\mathrm{V}_{\mathrm{S} 3}\left(\% \mathrm{~V}_{\mathrm{S} 1}\right)$ & 0 & 3 & 0 & 3 \\
\hline $\mathrm{V}_{\mathrm{S} 5}\left(\% \mathrm{~V}_{\mathrm{S} 1}\right)$ & 5 & 5 & 5 & 5 \\
\hline $\mathrm{V}_{\mathrm{S} 7}\left(\% \mathrm{~V}_{\mathrm{S} 1}\right)$ & 3 & 3 & 3 & 3 \\
\hline $\mathrm{V}_{\mathrm{S} 11}\left(\% \mathrm{~V}_{\mathrm{S} 1}\right)$ & 2 & 2 & 2 & 2 \\
\hline $\mathrm{V}_{\mathrm{S} 13}\left(\% \mathrm{~V}_{\mathrm{S} 1}\right)$ & 1 & 1 & 1 & 1 \\
\hline $\mathrm{I}_{\mathrm{L} 5}(\%)$ & 5 & 5 & 5 & 5 \\
\hline $\mathrm{I}_{\mathrm{L} 7}(\%)$ & 3 & 3 & 3 & 3 \\
\hline $\mathrm{I}_{\mathrm{L} 11}(\%)$ & 2 & 2 & 2 & 2 \\
\hline $\mathrm{I}_{\mathrm{L} 13}(\%)$ & 1 & 1 & 1 & 1 \\
\hline \hline
\end{tabular}

Step 2) Maximize $\mathrm{f}\left(X_{\mathrm{L}}\right)$ by using any of the unconstrained methods and obtain the solution $X_{\mathrm{C}}^{*}, X_{\mathrm{L}}^{*}$. The golden section search method [12] can be applied for obtaining the optimal $X_{\mathrm{L}}^{*}$

Step 3) Test whether the solution $X_{\mathrm{C}}^{*}, X_{\mathrm{L}}^{*}$ is the optimum solution of the original problem. The algorithm will stop when a feasible point will be reached or when the relative change in the objective function is small.

$$
\varepsilon<10^{-6} \text {. }
$$

If $X_{\mathrm{C}}^{*}, X_{\mathrm{L}}^{*}$ is found to be optimum, terminate the process. Otherwise, go to the next step.

Step 4) Find the value of the next penalty parameter as

$$
\mu_{\mathrm{m}}^{(\mathrm{J}+1)}=\beta \mu_{\mathrm{m}}^{(\mathrm{J})}
$$

where $\beta<1$.

Step 5) Set the new value of $\mathrm{J}=\mathrm{J}+1$, take the new starting point as $X_{\mathrm{C}}^{*}, X_{\mathrm{L}}^{*}$, and go to step 2 .

\section{Simulated RESUlts}

Four cases of the industrial plant were simulated using the optimization method.

Harmonic contents of the supply voltage and the load harmonic current are arbitrarily selected.

The resistance to reactance ration of the power system impedance is assumed to be $10 \%$.

The resistance of the compensator reactor has been neglected due to its small value with respect to its fundamental reactance [13].

The data of the four cases are given in Table I.

Fig. 3 shows the improvements in choosing the value of $X_{\mathrm{L}}$ during the search method and how it affects the objective function.

Table II shows that additional harmonic content results in lower PF and higher VTHD. This is caused by the increase in compensated line current due to the additional harmonics.

The most important concepts to be illustrated involve the evaluation of harmonic current limits at individual customers and harmonic voltage limits on the overall system. These 


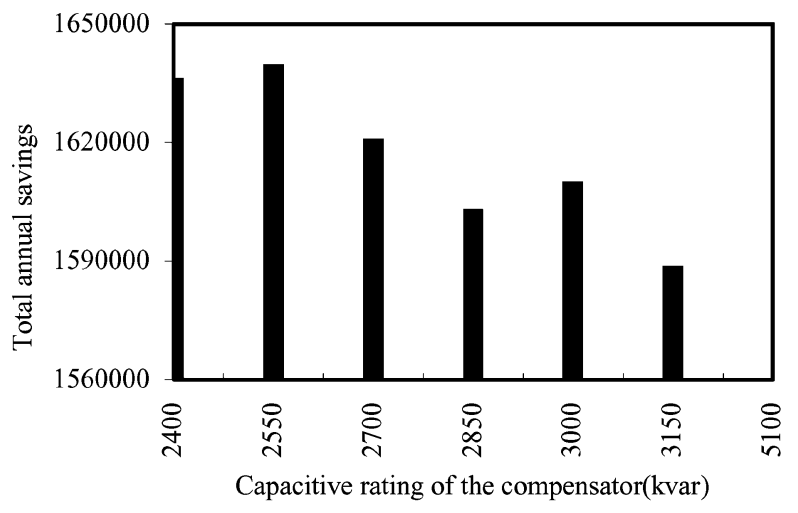

(a)

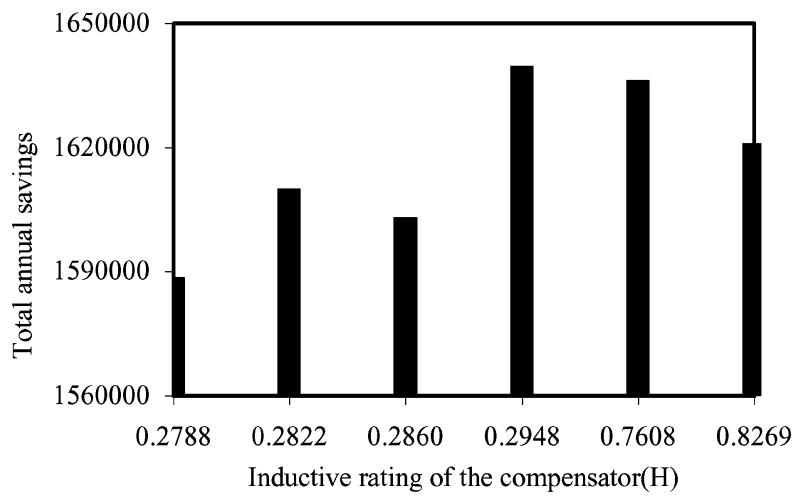

(b)

Fig. 3. Global maximum points for case 3 during the search method.

TABLE II

PF AND VOLTAGE TOTAL HARMONIC DisTORTION OF THE DIFFERENT CASES

\begin{tabular}{c|c|c|c|c}
\hline \hline CASE & Q $_{\mathrm{C}}(\mathrm{kvar})$ & $\mathrm{X}_{\mathrm{L}}(\Omega)$ & PF (\%) & VTHD (\%) \\
\hline 1 & 2850 & 0.8632 & 94.68 & 5.41 \\
\hline 2 & 2850 & 0.9697 & 94.67 & 5.90 \\
\hline 3 & 2550 & 0.2948 & 90.26 & 2.46 \\
\hline 4 & 2550 & 1.0533 & 99.22 & 5.83 \\
\hline \hline
\end{tabular}

limits are typically evaluated at the point of common coupling between the supplier and the customer. The objectives of the nonlinear load harmonic current limits are to limit the individual harmonic voltage to $3 \%$ of the fundamental voltage, and total harmonic distortion of the voltage to $5 \%$ [14].

Table III shows that the resultant values all come out well within standard limits.

Now, we test the displacement power factor (dPF), the supply current $\left(I_{\mathrm{S}}\right)$, the network transmission efficiency $(\eta)$, and the loss in Thevenin resistance (TL) as shown in Tables IV-V.

The advantages of the presented method consist of less harmonic power in secondary cables, lines, and switchgear owned by the end user, and it results in higher $\mathrm{dPF}$, lower $I_{\mathrm{S}}$, lower TL, and higher $\eta$ compared with the uncompensated case.

The advantages of the presented method over the conventional approaches as mentioned above include the improvement in the accuracy of the solution and in the ability of the developed algorithm to guarantee convergence to the optimal solution. Using this method, the global optimal solution as well as the local optimums are determined. This additional information
TABLE III

LOAD VOLTAGE HARMONICS FOR CASE 3

\begin{tabular}{l|c|c}
\hline \hline $\mathrm{K}$ & $\mathrm{V}_{\mathrm{LK}}(\mathrm{V})$ & $\% \mathrm{~V}_{\mathrm{LK}}$ \\
\hline 1 & 2314.703 & 100.00 \\
\hline 5 & 19.209 & 0.83 \\
\hline 7 & 36.364 & 1.57 \\
\hline 11 & 34.414 & 1.49 \\
\hline 13 & 19.203 & 0.83 \\
\hline \hline
\end{tabular}

TABLE IV

PERFormance of DifFERENT CASES BEFore COMPENSATION

\begin{tabular}{c|c|c|c|c}
\hline \hline CASE & dPF (\%) & $\mathrm{I}_{\mathrm{S}}(\mathrm{A})$ & $\eta(\%)$ & $\mathrm{TL}(\mathrm{kW})$ \\
\hline 1 & 71.65 & 953.64 & 99.34 & 10.49 \\
\hline 2 & 71.65 & 953.72 & 99.34 & 10.50 \\
\hline 3 & 71.65 & 924.14 & 98.77 & 18.47 \\
\hline 4 & 71.65 & 924.22 & 98.77 & 18.48 \\
\hline \hline
\end{tabular}

TABLE V

PERFoRMANCE OF DifFERENT CASES AFTER COMPENSATION

\begin{tabular}{c|c|c|c|c}
\hline \hline CASE & dPF (\%) & $\mathrm{I}_{\mathrm{S}}(\mathrm{A})$ & $\eta(\%)$ & $\mathrm{TL}(\mathrm{kW})$ \\
\hline 1 & 95.22 & 734.11 & 99.62 & 6.22 \\
\hline 2 & 95.59 & 734.83 & 99.62 & 6.23 \\
\hline 3 & 91.19 & 755.45 & 99.22 & 12.34 \\
\hline 4 & 90.80 & 754.59 & 99.22 & 12.32 \\
\hline \hline
\end{tabular}

TABLE VI

PAYBACK PERIOD ANALYSIS

\begin{tabular}{c|c|c|c}
\hline \hline CASE & TCOST (LE) & S $_{\text {I }}$ LE) & T (years) \\
\hline 1 & 270972 & 1878454 & 0.14 \\
\hline 2 & 297015 & 1874802 & 0.16 \\
\hline 3 & 184615 & 1639318 & 0.11 \\
\hline 4 & 215049 & 1649524 & 0.13 \\
\hline \hline
\end{tabular}

can be useful for performing a cost-benefit decision analysis before implementing the optimal LC compensator. A simple analysis can be performed using the simple payback period method.

Payback period is the period of time required for the profit or other benefits from an investment to equal the cost of the investment. In all situations, the criterion is to minimize the payback period. The computation of payback period $T$ is given by the following equation [1]:

$$
\mathrm{T}=\frac{\mathrm{TCOST}}{\mathrm{S}_{\mathrm{I}}} \text { years. }
$$

Table VI shows that an additional harmonic content results in a cost increase for obtaining the same power factor. This is caused by the increase in compensator rating due to the additional harmonics. Also, paybacks of less than one year can be expected.

\section{CONCLUSIONS}

A mathematical model for determining an optimal LC shunt compensator value at nonsinusoidal busbars including the criterion of maximizing total annual savings resulting from the PF 
correction is developed. The choice of the compensator value is constrained by the values that may cause resonance.

The Penalty Function approach is an effective tool for designing the optimal LC shunt compensator to meet the requirements needed for using only one objective function. This approach can reveal system designs which lead to very low PF, which cannot be improved beyond some practical value.

The presented method performs two major tasks: to produce a certain level of reactive power, and to provide a low impedance path for harmonic currents that must be confined. Both requirements listed have a strong impact on the total cost of the LC compensator.

Ongoing research effort consists of the modification and application of this method to take into account load profiles, other constraints (for example, the allowable overloads for capacitor imposed by the standard or recommendations), and probability density function of several indices as well known in recent international standards; for example IEC 1000-3-6.

\section{REFERENCES}

[1] M. M. Abdel Aziz, E. E. A. El-Zahab, and A. F. Zobaa, "Power factor and your electrical utility bill in Egypt," IEEE Trans. Power Del., vol. 18 , no. 4 , pp. $1567-1568$, Oct. 2003.

[2] Industrial Power Systems Data Book, General Electric Company, USA, 1985.

[3] M. M. Abdel-Aziz, E. E. A. El-Zahab, A. M. Ibrahim, and A. F. Zobaa, "Comparing capacitive and $L C$ compensators for power factor correction," in Proc. 10th Int. Conf. Harmonics Quality Power, vol. 1, Rio de Janeiro, Brazil, Oct. 6-9, 2002, pp. 42-45.

[4] IEEE Guide for Harmonic Control and Reactive Compensation of Static Power Converters, IEEE Std. 519-1981, 1981.

[5] R. P. Stratford, "Harmonic pollution on power system-A change in philosophy," IEEE Trans. Ind. Appl., vol. 16, no. 5, pp. 617-623, Sep./Oct. 1980.

[6] R. C. Dugan, M. F. McGranaghan, and H. W. Beaty, Electrical Power Systems Quality. $\quad$ New York: McGraw-Hill, 1996.

[7] P. F. Ribeiro, "Tutorial on harmonics modeling and simulation," in Proc. IEEE Power Eng. Soc. Winter Meet., Tampa, FL, Feb. 1998.

[8] D. E. Rice, "Adjustable speed drive and power rectifier harmonics their effect on power system components," in Proc. IEEE Petroleum Chemical Industry Committee Annu. Conf. San Francisco, CA, 1984.

[9] IEEE Standard for Shunt Power Capacitors, IEEE Std. 18-2002, 2002.

[10] D. A. Pierre, Optimization Theory with Applications. New York: Wiley, 1969.

[11] G. H. Hadley, Nonlinear Programming and Dynamic Programming. Reading, MA: Addison-Wesley, 1964.

[12] S. S. Rao, Engineering Optimization: Theory and Practice, 3rd ed. New York: Wiley-Interscience, 1996.
[13] G. G. Richards, O. T. Tan, P. Klinkhachorn, and N. I. Santoso, "Costconstrained power factor optimization with source harmonics using $L C$ compensators," IEEE Trans. Ind. Electron., vol. 34, no. 2, pp. 266-270, May 1987.

[14] IEEE Recommended Practices and Requirements for Harmonic Control in Electrical Power Systems, IEEE Std. 519-1992, 1992.

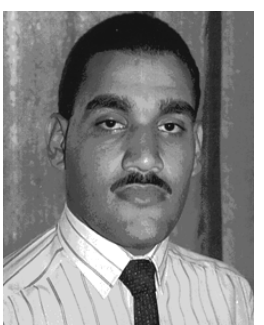

Ahmed Faheem Zobaa (M'01-SM'04) received the B.Sc. (Hons.), M.Sc., and Ph.D. degrees in electrical power and machines from the Faculty of Engineering at Cairo University, Giza, Egypt, in 1992, 1997, and 2002, respectively.

Currently, he is an Assistant Professor in the Department of Electrical Power and Machines with the Faculty of Engineering, Cairo University. He was an Instructor in the Department of Electrical Power \& Machines, with the Faculty of Engineering at Cairo University from 1992 to 1997 and Teaching Assistant from 1997 to 2002. He regularly reviews papers for eight IEEE Transactions especially all IEEE/PES transactions and seven journals in his areas of interest. He is author or co-author of many refereed journal and conference papers. His areas of research include harmonics, compensation of reactive power, power quality, photovoltaics, wind energy, education and distance learning. He is an Editorial Board member for Electrical Power Quality and Utilization Journal, Electric Power Components \& Systems Journal and International Journal of Computational Intelligence. He is an Editor for IEEE Power Engineering Letters and IEEE TRANSACTIONS ON ENERGY CONVERSION. Also, he is an Associate Editor for IEEE TRANSACTIONS ON INDUSTRIAL ELECTRONICS, International Journal of Power and Energy Systems, International Journal on Modeling and Simulation, and Neurocomputing Journal.

Dr. Zobaa is a member of the IEEE Power Engineering/Industry Applications/Industrial Electronics/Power Electronics Societies, the Institution of Electrical Engineers, International Association of Science and Technology for Development and the International Solar Energy Society.

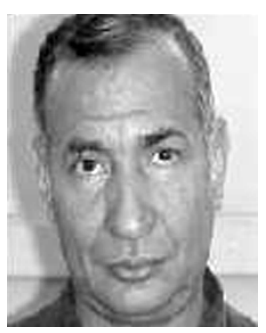

Mohamed Mamdouh Abdel Aziz (M'80) received the B.Sc. (Hons.), M.Sc., and Ph.D. degrees in electrical power and machines, Cairo University, Giza, Egypt, in 1970, 1972, and 1975, respectively.

Following graduation, he was an Instructor in the Department of Electrical Power and Machines, Cairo University, from 1970 to 1972 and was a Teaching Assistant in the Department of Electrical Power and Machines, Cairo University, from 1972 to 1975 . Currently, he is a Professor in the Department of Electrical Power and Machines, Cairo University. He is author or coauthor of many refereed journal and conference papers. Areas of research include cables, contact resistance, harmonics, power quality, photovoltaic systems, and wind energy systems..

Dr. Abdel Aziz has been a member of the Institute of Electrical and Electronics Engineers. 